\title{
CCLXXXIII. BANDA.
}

\section{Maart 1664. ${ }^{1}$ )}

„Den 3en Februarij is de fluijt, Loenen, met een chaloup na Damme gesonden, met ordre om Nile en passant aen te doen tot verder distructie van de noteboomen ${ }^{2}$ ) [en] afweering der Macassaren.... Sullende op alle de eijlanden ook verniewt worden het oude verbond van submissie, om d'Engelsen te voorcomen, stellende op elke plaets een groote steen met Comp ${ }^{s}$ wapen ende merk, met een prince vlagge, etc.... Hebben ook op Seroua omgekapt 83 vruchtdragende boomen en een goet getal jonge spruijten...." (Dagh-Register 1664, 231, v, 402).

In den jare na s'werelts geboren heijl den Emanuel ${ }^{3}$ ) Jesus Christus 1664, op den 6e Martij, hebben wij (afgesondene van den E. heer Johan van Dam, Raat Extraordinair van India, Gouverneur en Directeur der kostelijke eijlanden Banda), Jacob Sas, schipper ende opperhooft, Jan van der Linde, sergeant ende militaire hooft, Isbrant Petrus Ermunt, adsistent, Martijn Claas Trouw, stierman, ende den provisioneelen sergeant Michiel Hendrix, door hoog gemelten sijn $\mathrm{E}^{s}$ welgegeven ordre, uijt den name van $d^{\prime} E^{\circ}{ }^{\circ}$ Heer Joan Maatsuijcker, Gouverneur Generael over gants Nederlants Orienten, van wegen den E. Vereenigden Nederlantschen staat in 't Oosten, aan d'eene sijde, ende d'Orangcaijs des eijlants Serouwa ${ }^{4}$ ) voor haar selven, hare successeuren ende onderdanen, aan d'ander sijde, een eeuwig duijrend verbont, te samen opgeregt in maniere en op conditien als volgt.

1. Dat de orangcaijen van Serouwa, ook uijt den naam van hare successeuren ende onderhorige, haar selven stellen tot onderdanen aian d'honorable Nederlantse Oost-Indische Comp'.

2. Dat sij haar selven verbinden, geene andere natien, 't sij blancke ofte swarte, als alleen de Hollanders op hare stranden (veel min op) haar eijlant) te admitteren.

3. Dat veel weijniger hare specerijen aan eenige andere volckeren, dan alleen aan d'hoog gemelte E. Comp' sullen laten toecomen.

1) Uit het Contractboek.

2) Muskaatnoten.

3) Naam aan Christus gegeven in Jesaja, VII, 14. Hij beteekent: God met ons. (Christelijke Encyclopuedie, II, bldz. 83).

4) Een der N.O. van de Zuid-Wester-eilanden. 
4. Dat alle muscaatboomen, die sij weten ofte sullen comen te weten, aldlaar te staan, aan d'Hollanders daar comende, sullen ontdekken, en in hare tegenwoordigheijt omslaan voor den geaccordeerden prijs, op pene van gehouden te werden als ongehoorsame onderdanen en verbontbrekers.

5. Dat daar voor d'E. Comp ${ }^{\circ}$ de bescherminge ende heerschappije aanneemt over haer, tegen alle en een ijcler, die haer eenige schade ofte leet aandoen ofte willen, als sij Serouwers sulx versoeken, belovende de hoog gemelte E. Compr voorder haar met alle vruntschap te bejegenen, als een goet heer sijne onderclanen schuldig is te cloen.

Deze bovenstaande articulen worden wedersijts belooft, sonder Eenige de minste infractie in alles punctuelijck nagecomen en de agtervolgt te sullen werden, doende de orangcaijs ende inwoonders van .... ${ }^{1}$ ) ingevolge bij desen per hare gewoonlijcke formaliteijten, solemnelijck aan de E. Comp ${ }^{c}$ den eedt van getrouwe onderdanigheiji, waarop aen de selve een vlagge, waer in die onderdanigheijt staat liijtgedrukt, neffens een steene voet, waerin hooggemelte E. Comps wapen en merk is uijtgehouwen, wordt behandigt, en bij haar wordt aengenomen, om daardoor sig selven als sodanig aan alle aancomencle volckerèn te vertoonen.

Aldus gedaan en vastgestelt op 't eijlant Serouwa den $6^{\circ}$ Martij A' 1664 en van dese onderstaande Orangcaijs geteekent: dit is 't merck van orangcaij Saijse, orangcang Monij, orangcaij Marasij, orangcaij Ablau, Jacob Sas, Jan van der Linde, Isbrant Petrus Ermunt, Martijn Claeszoon Trouw en Michiel Hendrix.

\section{BANDA.}

\section{Maart 1664. " )}

De fluit Loenen deed volgens haar „ordre” Damar aan om ook dacr het gezag onzer O. I. C. te bevestigen. (Vgl. Corp. Dipl. I, bldz. 475, v.r.: 1)agh-Rcyister 1664, bldz. 231 v.v.). De Engelschen beweerden spoedigs daarna „dit eiland in possessie genomen" te hebben, een bericht, dat juist bleek te zijn, ook voorzoover Nila betreft. „De meeste part der inhabitanten van 't eijlant Damme hebben haer vrijwillig gestelt onder de pro-: tectie van zijn Maijt Charles de Secunde", schreven de Fngelsche vain

1) ?

$\Rightarrow$ Uit het Contractboek. 